\title{
Ectopic Expression of Thy-1 in the Kidneys of Transgenic Mice Induces Functional and Proliferative Abnormalities
}

\author{
George Kollias," David J. Evans, $\ddagger$ Mary Ritter, $§$ \\ Jackie Beech, ${ }^{\dagger}$ Roger Morris, ${ }^{\dagger}$ and Frank Grosveld ${ }^{\star}$ \\ "Laboratory of Gene Structure and Expression \\ tLaboratory of Neurobiology and Development \\ National Institute for Medical Research \\ The Ridgeway, Mill Hill, London NW7 1AA England \\ †Department of Histopathology \\ $\$$ Department of Immunology \\ Royal Postgraduate Medical School \\ Hammersmith Hospital \\ London W12 OHS England
}

\section{Summary}

Hybrid human-mouse Thy-1.1 genes were injected into pronuclei of Thy-1.2 mice to produce transgenic animals. A hybrid gene composed of the $5^{\prime}$ part of the mouse Thy-1.1 gene combined with the 3 ' human untranslated regions was expressed abnormally in the kidney podocytes, which resulted in severe proteinuria and subsequent death in several founder mice. A hybrid Thy-1 gene composed of the human coding reglon with the $5^{\prime}$ and $3^{\prime}$ flanking reglons of the mouse gene was expressed abnormally in a different part of the kidney (the tubular epithelia), which resulted in a proliferative kidney disorder. In addition, a neoplasm was found in the brain of one of these mice. These results show that the Thy-1 protein can play an important role in the activation, proliferation, and differentiation of many different cell types.

\section{Introduction}

The Thy-1 gene is a member of the Ig superfamily of genes (Williams, 1985) and is expressed in many different cell types. The cell-surface glycoprotein (17 kd) is anchored to the cell membrane via a glycophospholipid (Williams and Gagnon, 1982; Low and Kincade, 1985; Tse et al., 1985), a property shared by an increasing number of other cell-surface proteins (for review, see Low et al., 1986). The antigen has a very complicated expression pattern, but was first characterized as a murine T lymphocyte-specific antigen (Reif and Allen, 1964). In the mouse it is also found on lymphocyte precursors, including pluripotential hematopoietic stem cells (Ritter et al., 1980; Mulier-Sieburg et al., 1986), fibroblasts, and most neurons in the central nervous system (see review, Morris, 1985). In humans, Thy-1 is also expressed in neurons and in populations of early T and B cells (Ritter et al., 1983); however, it is absent from T lymphocytes (Ritter et al., 1983) and is present at high levels in kidney (Dalchau and Fabre, 1979). The rat shows a mixture of the human and mouse patterns of expression; it is expressed in brain, in early $T$ and $B$ cells, and in the kidney mesangial cells (Morris, 1985).

The function of the Thy-1 antigen is not known but it has been postulated to be involved in cell-cell recognition (Williams and Gagnon, 1982; Williams, 1985). Certainly Thy-1-specific antibodies can stimulate intracellular calcium levels and cause proliferation in mouse $T$ cells and in transfected B cells (Kroczek et al., 1986a, 1986b; Gunter, 1984). This has led to the suggestion that in T cells Thy- 1 has a proliferative function that is aritigen-independent (Kroczek et al., 1986b), taking place via the T3-dependent pathway (Gunter et al., 1987). However, if Thy-1 has a proliferative function in hematopoietic cells in general, it would be in very early pre-T cells, since it is not present in mature T cells in rat and in humans. In neurons, Thy-1 only appears well after proliferation has ceased, so that its role on these cells would not appear to be related to cell division (Morris and Beech, 1987).

The human and mouse Thy-1 genes have been cloned and characterized (Giguere et al., 1985; Ingraham and Evans, 1986; Ingraham et al., 1986; Seki et al., 1985). The mouse gene is possibly expressed from two promoters, resulting in different untranslated 5 ' leader sequences (Giguere et al., 1985; Ingraham et al., 1986). The promoter regions are not tissue-specific, lack a TATA box, and are contained in a methylation-free island (Giguere et al., 1985; Ingraham et al., 1986; Kolsto et al., 1986). Several tissue-specific extragenic and intragenic sequences are required for efficient and cell-type-specific expression (Giguere et al., 1985; Ingraham and Evans, 1986; Kollias et al., 1987). We have shown previously that a mouse-human Thy-1 gene can be expressed at high levels in nerve cells and thymocytes in transgenic mice (Kollias et al., 1987), although the gene was not expressed in peripheral $T$ cells. To define the cis-acting sequences that are involved in the tissue-specific expression of the Thy-1 gene, we introduced a number of mouse-human Thy-1 hybrid genes into the germline of mice. Analysis of the expression patterns of the Thy- 1 transgenes showed consistent expression in the mouse kidney tissues, normally negative for Thy- 1 in the mouse but positive in humans. We report that this inappropriate expression of Thy-1 leads to either kidney malfunction or kidney proliferative disorders and malfunction.

\section{Results}

Murine Thy-1 Expression in the Glomerulus Causes Proteinuria in the Transgenic Mice

The constructs shown in Figure 1 were injected into fertilized (CBA $\times$ C57BI) F1 mouse eggs (Thy -1.2 background) to obtain Thy-1.1, or human Thy-1 transgenic mice. The first construct $(T)$ contains the murine Thy-1.1 gene in which the $3^{\prime}$ untranslated region has been replaced with a similar region from the human Thy-1 gene. The mature protein resulting from this transgene is completely Thy-1.1 and can be distinguished from its allelic form, the endogenous Thy-1.2, by using monoclonal antibodies (Williams and Gagnon, 1982). This construct does not lead to correct expression in mature $T$ lymphocytes (Kollias et al., 


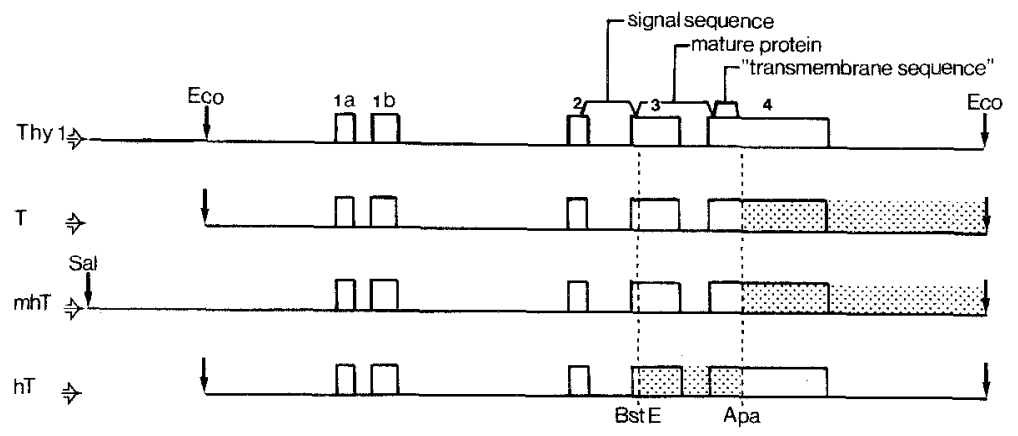

Figure 1. Human-Mouse Hybrid Thy-1 Genes The top line shows the murine Thy-1.1 gene with the different coding regions. The $T$ constructs were made by exchange of the nontransiated $3^{\prime}$ Apal-EcoRl fragments of the human and mouse gene. The $T$ hybrid gene coding region is entirely murine Thy-1, and was injected as an EcoRI fragment. The mhT construct is identical to the $T$ construct, but also contains $1.5 \mathrm{~kb} 5^{\prime}$ flanking sequences of the murine gene. It was injecled as a Sall-EcoR fragment. The hT hybrid gene was obtained by exchange of the homologous BstEll-Apal fragments of the human and mouse genes. The hT construct contains the murine leader sequences and the human mature protein coding sequences. The fragment was injected as an EcoRl fragment. Shaded areas indicate human DNA sequences.

1987), so a second construct (mhT) containing additional upstream sequences from the murine gene was made (Figure 1). The third construct (hT) contains the normal murine $3^{\prime}$ untranslated region, but the central part of the gene coding for the mature protein has been replaced with the homologous part of the human gene. Injections of the $T$ construct resulted in four transgenic mice, $T 6, T 9$, $\mathrm{T11}$, and T12. T6 had a very high level of expression of the transgene and died in infancy; T9 had a low level of expression and could be bred to a homozygous animal with similar expression patterns to $\mathrm{T} 11$ and $\mathrm{T} 12 . \mathrm{T} 11$ and $\mathrm{T} 12$ both had multiple copies of the transgene and expressed approximately six to ten times the normal level of Thy- 1 in the brain. The expression in lymphoid cells was abnormal (Kollias et al., 1987) and will be considered further elsewhere (Kollias, unpublished data). Surprisingly, the presence of the human $3^{\prime}$ end in the Thy-1.1 transgene caused expression in the kidneys of all these animals. Additional sequences at the $5^{\prime}$ end ( $\mathrm{mhT}$; Figure 1 ) did not change that pattern, and another transgenic animal (mhT4) with high expression levels in the kidney was obtained. Three other healthy (mhT) animals had nearly 10-fold lower levels of expression in the kidney on the same cell type. These animals did not show any abnormalities and will not be considered further. When transgene mRNA levels of $\mathrm{T} 11, \mathrm{~T} 12$, and $\mathrm{mhT} 4$ are compared with each other (Figure $2 a)$, it is clear that these animals express the transgene and the endogenous gene in brain (T12>T11 > mhT4), but only the transgene in kidney. Neither gene is expressed in liver (Figure 2a). All T12 mice and the first generation of mhT4 developed proteinuria after the first month of life, which culminates in severe kidney sclerosis. Different offspring of T12 were analyzed at different times during development to determine levels of Thy-1 mRNA in the kidney, and of proteinuria (Figures 2b, 2c). Between 30 and 36 days, which is the time of onset of the proteinuria (urine analysis, Figure 2c), there is an increase in transgenic mRNA in the kidney. By the time the animals develop a kidney sclerosis the apparent level of transgene mRNA has decreased, because of the destruction of Thy-1-ex- pressing cells (see below). At the same time, the level of endogenous Thy-1.2 increases above background, because of T lymphocyte infiltration.

Normal mouse kidney is immunohistochemically Thy-1negative (not shown; see also Morris and Ritter, 1980), so the very small amount of Thy-1, which can be measured by radioimmunoassay, arises either from a generalized, very low level of antigen expression, or from $T$ lymphocytes in the blood vessels. In contrast, all the T12, T11, and mhT4 mice examined contained an identical very heavy distribution of Thy- 1 in the glomeruli (Figure 3a) on podocytes (Figure $3 \mathrm{e}$ ). Endogenous Thy-1.2 remained undetectable immunohistochemically. Expression of the transgene in podocytes was found in T12 mice at 11 days (the earliest age investigated) and persisted through the onset and course of proteinuria development (Figures $3 \mathrm{a}, 3 \mathrm{c}$, 3d). None of the other cell types in the kidney, including the mesangial cells of the glomeruli, had detectable transgenic Thy-1.1 associated with them during this period.

The kidneys of the 20-and 30-day-old mice did not differ histologically or ultrastructurally from those of their littermates (Figure 4a). At 36 days, T12 transgenic mice showed minor degrees of (podocyte) foot process swelling (Figure $4 \mathrm{~b}$ ) and a slight mesangial deposition of $\mathrm{C} 3, \mathrm{lgM}$, and $\lg G$ with the same distribution as that found in the littermates (not shown). With increasing severity of proteinuria (Figure 2c), the animals showed extensive glomerular and tubular changes (Figures 3a, 3c, 3d; Figures 4c, 4d). The tubules became dilated (Figures $3 c, 3 d$ ) and were found to contain protein casts. The glomerular change is best summarized as a severe segmental sclerosis. Changes varied a great deal from glomerulus to glomerulus (Figures $4 c, 4 d$ ), with some glomeruli showing areas of lobular collapse and an increase of basement membrane-like material (Figure 4c). In others, electron dense deposits (Figure 4d), mostly in the mesangium but also occasionally as large subendothelial accumulations, were a prominent feature. Occasional foci of mesangial proliferation were seen. Extracapillary proliferation (crescents) and subepithelial deposits were not seen. In these severely damaged 
glomeruli there are marked podocyte abnormalities with foot process swelling and vacuolation (Figure 4d). Only then did the glomeruli show heavy deposits of $\operatorname{lgG}, \operatorname{lgM}$, and $\mathrm{C} 3$ in the mesangial regions.

The possibility that anti-Thy-1.1 antibodies might be a significant component of the immune response evident in the damaged kidneys was investigated using a sensitive radioimmunoassay. Serum from four $\mathrm{T} 12$ homozygous mice aged 8 weeks, which showed heavy proteinuria and severe kidney damage, was assayed for antibodies binding to both Thy-1.1 and Thy-1.2 thymocytes. To avoid any masking of anti-Thy-1.1 antibodies by immune complex formation, aliquots of each serum were diluted in $0.5 \mathrm{M}$ acetic acid to dissociate such complexes prior to incubation with thymocytes. No difference was found between such acid-treated serum and aliquots diluted in PBS. Two transgenic mice had titers on the Thy-1.1-type thymocytes that were indistinguishable from their littermates, or from their serum titered on Thy-1.2 thymocytes. The other two transgenic mice had the same titer as the rest, but at the lowest dilutions showed slightly higher binding to the Thy1.1-type thymocytes. By comparison with control anti-Thy1.1 antibodies, this was equivalent to $0.04 \mu \mathrm{g}$ of antibody per $\mathrm{ml}$ (approximately $2.10^{-4} \%$ of total serum Ig). Serum from four heterozygotic T12 mice and their littermates at 28 days of age again showed no differences.

\section{Expression of Human Thy-1 in Murine Kidney Induces Proliferative Abnormalities of Proximal Tubular Epithelium}

Injection of the hT construct (Figure 1) resulted in ten positive transgenic mice. Three of these, hT27, hT6, and hT16, were alive and apparently normal, and hT27 was analyzed in detail. Two of the mice, $\mathrm{hT} 1$ and $\mathrm{hT} 8$, died before they could be analyzed; the remaining five mice, hT10, hT13, $\mathrm{hTd} 1, \mathrm{hTd} 4$, and hTd5, also died, but could be analyzed in detail for the expression of Thy-1. S1 nuclease analysis (Figure 5), using probes for the human Thy-1 gene and the endogenous Thy-1.2 gene, shows that high levels of expression of the transgene Thy-1 are found in the brain and kidney, while the endogenous Thy-1 RNA is found only in the brain. Again, liver does not show expression of either gene. By radioimmunoassay the kidneys were discovered to express a level of human Thy-1 comparable to that expressed by normal human brain (Table 1). hT10, hT13, hTd1, hTd4, and hTd5 all developed a cystic neoplasm of Thy- 1 . positive cells, while hT27 has no apparent abnormalities. This is not due to a lack of transcription of the transgene, since hT27 expressed high levels of intact mRNA (Figure 5 and Northern blots, not shown), but probably to a secondary mutation in the gene, since very little human Thy-1 could be detected immunohistochemically.

The kidneys of $\mathrm{hT} 10$ and $\mathrm{hT} 13$ were analyzed histologically and immunohistochemically. Both showed neoplasms derived from the proximal tubules through an intermediate in situ tumor. Many tubules show cystic dilation (Figure 3f). In some, usually larger, dilated tubules, the epithelium maintains a monolayer and is Thy-1-negative (Figure 3 h). In other tubules, the epithelia have very heavy Thy -1 deposits at their luminal surface (Figures 3h, 3i), with cells often showing an unusual degree of nuclear variability, an increase in nuclear size, and a high mitotic rate, leading to closure of the tubules (Figure $3 \mathrm{~h}$ ). In contrast to the earlier mice containing the $\mathrm{T}$ and $\mathrm{mhT}$ constructs, podocytes in hT10 and hT13 kidneys were Thy1-negative (Figure 3g). However, the Thy-1-positive in situ lesions often extended into glomeruli, which confirmed the proximal tubular origin of the lesion. In addition, analysis of brain tissue of $h T 13$ revealed a papillomatous neoplasm of the choroid plexus (Figure 6) that filled the third and fourth ventricles. The cells showed cytological atypia, which we have not yet analyzed in detail.

\section{Tubular Epithelium Expressing Thy 1 is Immortalized in Culture}

Part of an hT10 kidney was put into culture, where a number of morphologically different cell types (Figure 7a) proliferated rapidly. Cell lines were derived by repeated (two to four) sequences of limiting dilution cioning. Control kidney suspensions cultured at the same time proliferated more slowly and stopped growing completely after 10 weeks of continuous culture. We could show that the ht10 neoplastic cells are of epithelial origin by the following criteria: all cell lines were positive for cytokeratin (e.g., Figure $7 \mathrm{~g}, 7 \mathrm{~h}$ ) and for the monoclonal 4F1 (Figure $7 \mathrm{f}$ ) to thymus cortical epithelia, which also reacts with kidney tubular epithelia in vivo (Ritter, unpublished data). Moreover, all were negative (or very low) for endogenous Thy-1.2, unlike fibroblasts (Stern, 1973). Interestingly, an extensive range of cell types could be isolated by using different criteria: morphology (Figures $7 \mathrm{~b}-7 \mathrm{e}$ ), proliferation rate (18-48 hr), fibronectin expression (some exclusively cellular, others incorporating it into the extracellular matrix; Figures $7 \mathrm{i}, 7 \mathrm{j}$ ), and the presence of the enzyme $\mathrm{D}$ amino acid oxidase. This enzyme is present in tubular epithelium but not in fibroblasts (Gilbert and Migeon, 1975), and can be selected for in media that contain the $D$ form of valine only. Although identical to each other by the criteria mentioned above, both resistant and sensitive cell lines were isolated. The uncloned cells had abundant human Thy-1 mRNA (Figure 2) and high Thy-1 levels, as measured by radioimmunoassay (Table 1). Each of the 36 different cell lines that have been derived expresses human Thy-1, in levels ranging from $15 \%-90 \%$ of the level found in normal human brain (Table 1). Neither the original uncloned cells nor any of the lines (six to date) give transplantable tumors when introduced into the peritoneal cavity or subcutaneously in nude mice.

\section{Discussion}

Two purposes can be served by the production of transgenic mice: the elucidation of tissue-specific regulatory elements for the gene under study and the analysis of the biological role of the gene product. Both aspects are illustrated by our study. By constructing human--mouse hybrid Thy-1 genes, we exploited the extensive differences in tissue-specific expression that occur between these two species. In particular, Thy-1 is virtually absent from murine kidney (Reif and Allen, 1964; Morris and Ritter, 1980), 
a

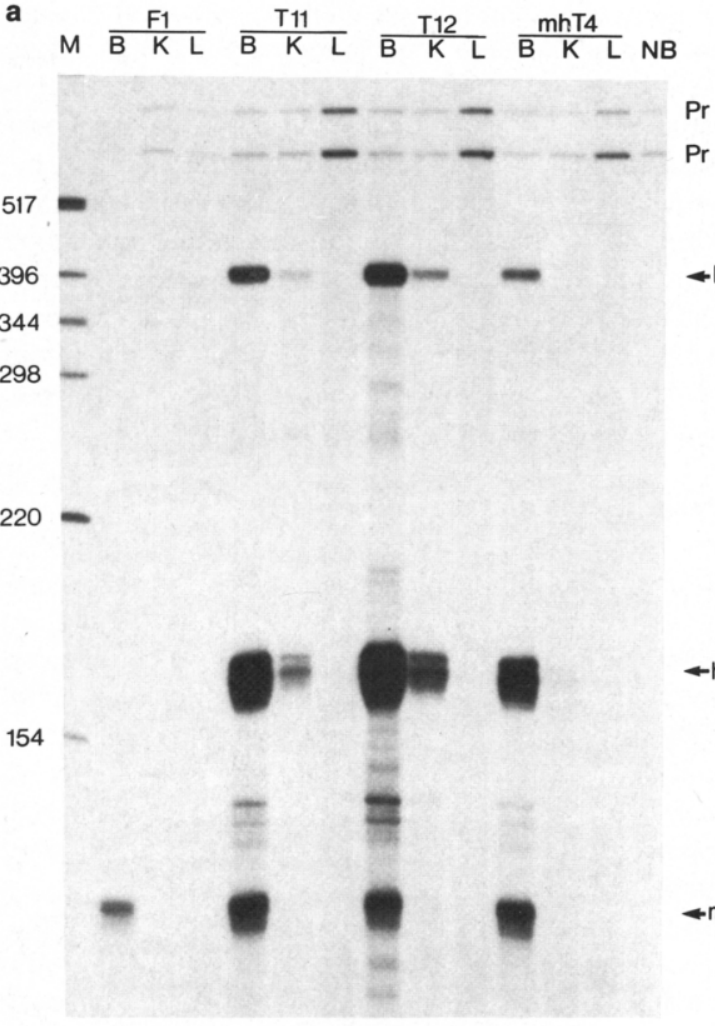

b

$\mathrm{F} 1 \mathrm{Mr} \frac{\mathrm{T} 11}{3036 \mathrm{~A}} \frac{\mathrm{T} 12}{30363636 \mathrm{~A}} \frac{\mathrm{F} 1}{2036 \mathrm{mhT}} \mathrm{A}$ $p \rightarrow p \rightarrow p \rightarrow s$

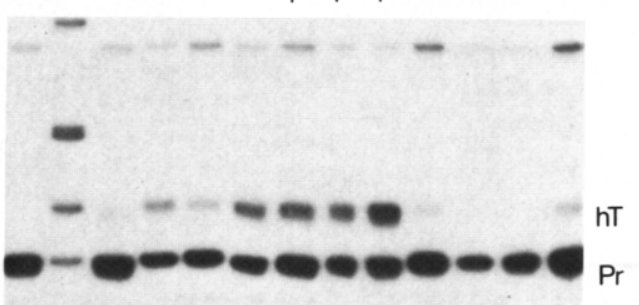

$-$

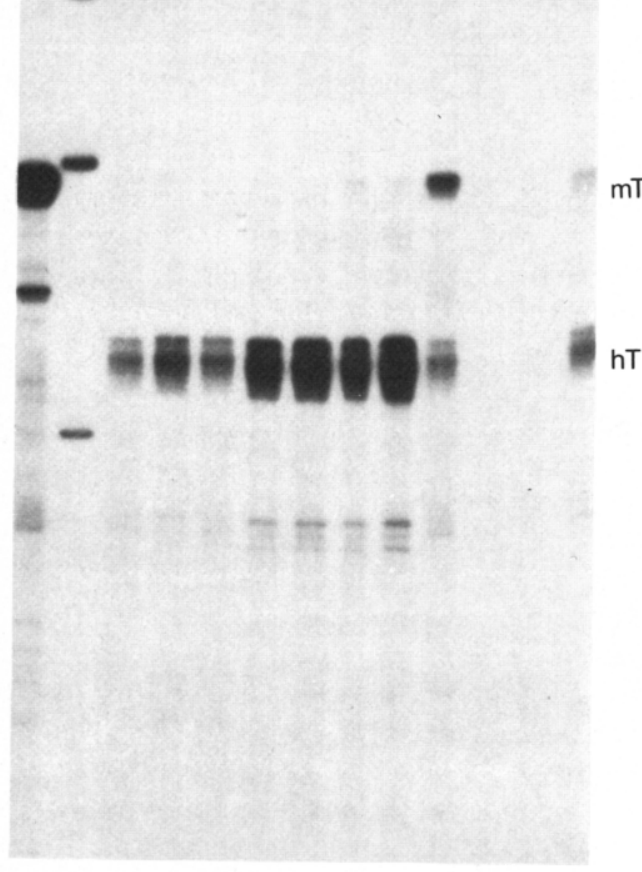

1 mhT4

C T11 T12 A 2036 A hT13 hT10

$\begin{array}{lllllllllllll}30 & 36 & \text { A } & 30 & 36 & 36 & 36 & \text { A } & 20 & 36 & \text { A } & \text { hT13 } & \text { hT10 }\end{array}$

Figure 2. Expression of Thy-1 in Transgenic Mouse Brain and Kidney

(a) Measurement of steady-state RNA levels of transgenic mouse tissues carrying the T and mhT gene construct. Ten micrograms of RNA brain (B), kidney (K), liver (L), and a human neuroblastoma cell line expressing low amounts of human Thy-1 mRNA (NB). The endogenous Thy-1.2 RNA is detected as a 115 nucleolide band (mT) and the transgene RNA as a 165 and 400 nucleotide band (hT; see Experimental Procedures). mhT4 Thy-1 


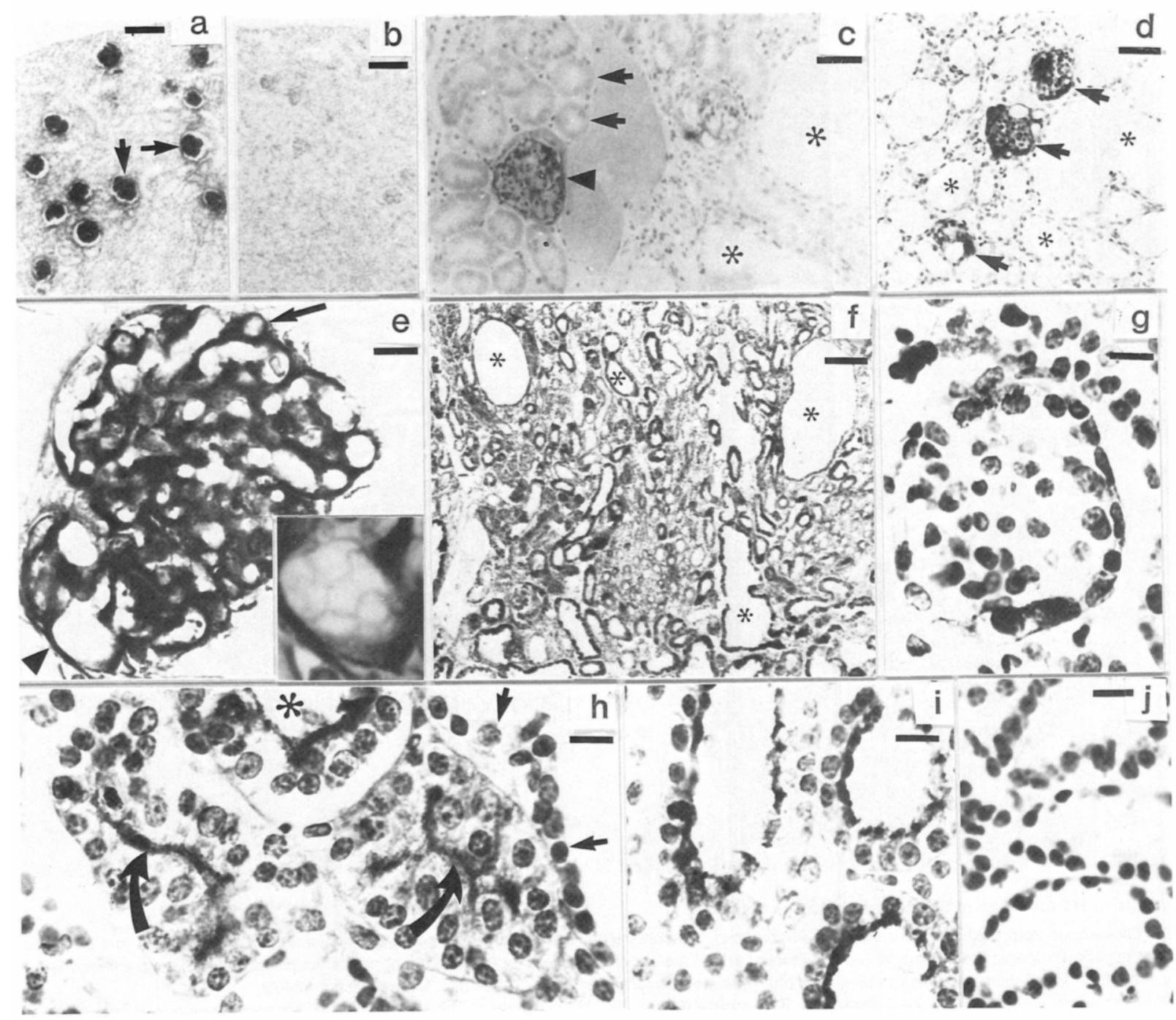

Figure 3. Immunocytochemistry for Transgenic Thy-1 in Kidneys of T12 (a-e) and hT10 (F-i) Mice

Immunoperoxidase staining for Thy-1.1 (a-e) or human Thy-1 (f-j) with thionin counterstaining of nuclei. (a) Cortex of a heterozygous 36-day-old T12 mouse showing very heavy immunolabeling of glomeruli (e.g., arrows). (b) Control section labeled with second antibody alone. (c) T12 heterozygous mouse, at 3 months old, showing highly dilated tubules developing (asterisks at right), while the tubules (arrows) and Thy-1.1-labeled glomerulus (arrowhead) on the left are still relatively normal. (d) Homozygous 3-month-old mouse, extensive tubular dilation (e.g., asterisks) around three Thy-1.1labeled glomeruli (arrows). (e) Thy-1.1 labeling of podocytes in glomerulus of a 2-month-old heterozygote. An immunolabeled cell (arrow) extends its process into the glomerulus; another podocyte process can be seen terminating on a capillary (arrowhead), which at higher magnification (inset) can be seen to contain erythrocytes. (f) Immunolabeling of dilated tubules (e.g., asterisks) in hT10 kidney. (g) Glomerulus (hT10) lacks staining for human Thy-1. (h) The monolayer of tubular epithelium (arrows) of a large cystic tubule is not labeled for human Thy-1, contrasting with heavy immunolabeling at the luminal face of three smaller tubules, two of which have been closed by epithelial proliferation (curved arrows; asterisk shows open Thy-1 lined tubule). (i) Immunolabeling at luminal surface of three tubules. (j) Control section, labeled with second antlbody alone. Scale bars are $100 \mu \mathrm{m}$ in (a) and (b); $50 \mu \mathrm{m}$ in (c), (d), and (t); and $10 \mu \mathrm{m}$ in (e) and (g)-(j).

but is present at substantial levels (Dalchau and Fabre, 1979 ) in human kidney. Since the T construct introduced into transgenic mice gave high levels of Thy-1.1 product in the kidney (Kollias et al., 1987), it seemed opportune to examine the effect of further human-mouse hybrid Thy-1 genes on kidney expression and function.

RNA in the kidney is easily visible at higher exposures (see Figure 2b). (b) Expression of $T$ and mhT transgenic mRNA in mouse kidney tissues at several points in development. Br, normal F1 mouse brain RNA. 20, 30, and 36 denotes postnatal development in days. "A." signifies adult (7- to 10-week-old animals). The sequence $p \rightarrow p \rightarrow p \rightarrow s$ denotes otherwise healthy $T 12$ animals with increasing levels of proteinuria advancing to very sick (S) aduit animais (see also Figure 2c). The S1 analysis was carried out as in (a) except that the Hinfl probe for the Thy-1.2 RNIA was used (see Experimental Procedures). (c) SDS-polyacrylamide gels showing development of proteinuria in T12 transgenic mice (Figure 2b). Urine (5 $\mu$ ) was electrophoresed under nonreducing conditions, and the gels were stained with Coomassie blue. 30, 36, and A are as described in Figure $2 \mathrm{~b}$. Molecular weight markers were reduced samples of ovalbumin ( $43 \mathrm{~K})$, bovine serum albumin (68K), human transferrin ( $78 \mathrm{~K}$ ), and rabbit muscle phosphorylase $B(93 K)$. 


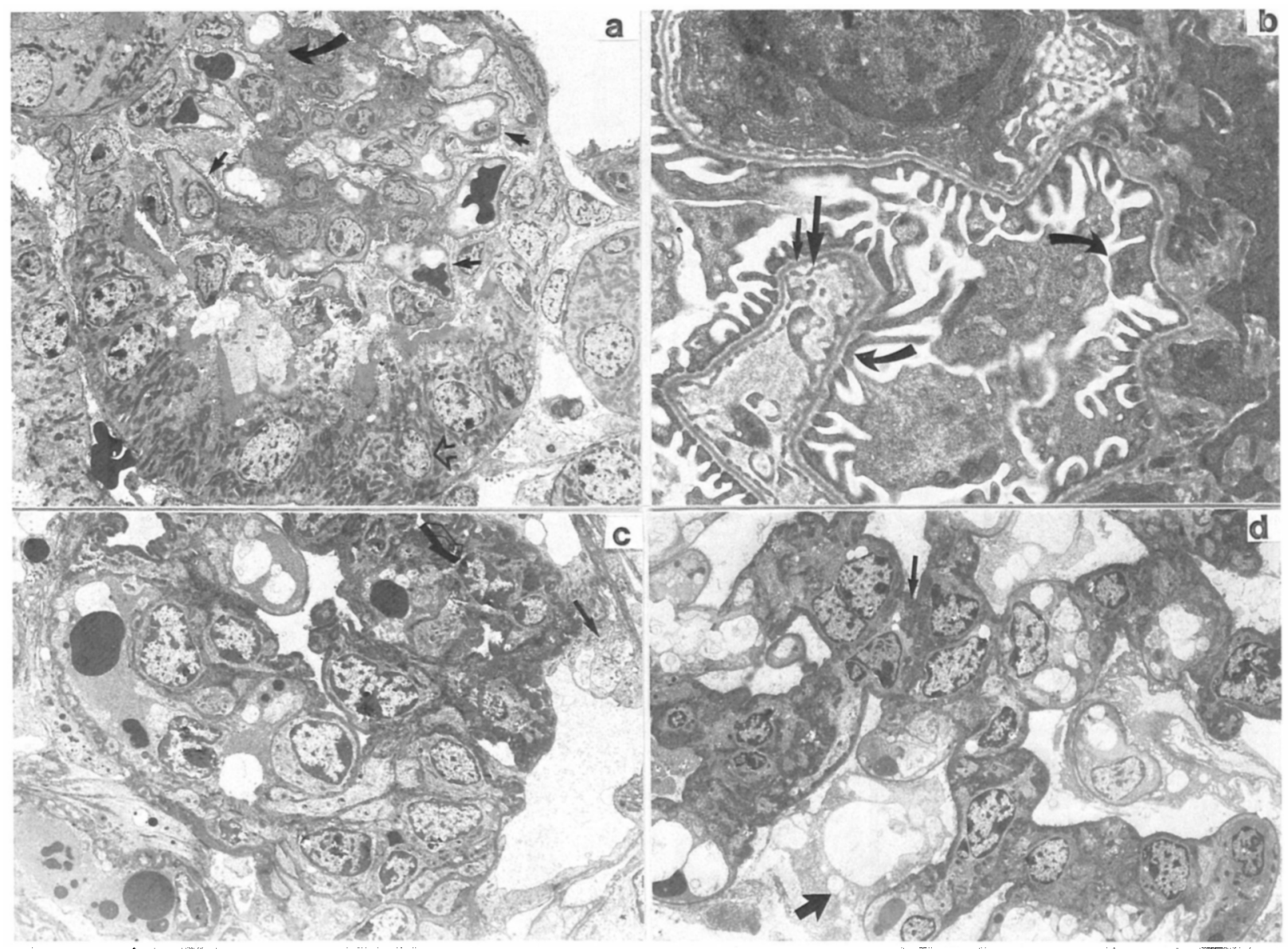

Figure 4. Ultrastructure of the Transgenic Mouse Kidney

(a) Glomerulus from a 20-day-old transgenic T12 mouse. The glomerulus appears normal. The podocytes (small arrows) have fine foot processes on the capillary loops; the mesangial regions (curved arrow) are of normal cellularity and contain normal amounts of matrix. The mitochondria-rich cells (open arrow) lining Bowman's capsule at one pole are normally present in the mouse. Magnification, 1246x.

(b) High-power view of a 36-day-old transgenic (T12) mouse (Figure 3a) with proteinuria. The capillary basement membrane (small arrow) and endothelium (larger arrow) are normal. Most of the foot processes (curved arrows) appear normal, though some appear swollen. Magnification, 8566.25x.

(c) Glomerulus from an mhT4 animal with renal failure showing segmental collapse (open arrow). There is an increase of basement membrane-like material and electron dense deposits. Podocytes are difficult to find (small arrow) and have a vacuolated cytoplasm. Magnification, 1993.6x. (d) Glomerulus from a T12 animal with renal failure. Electron dense deposits in the mesangium (small arrow) are a prominent feature. Podocytes are grossly abnormal with marked vacuolation (large arrow). Transgenic T12. Magnification, 2492x.

We have shown that both the T and $\mathrm{mhT}$ constructs give high levels of transgenic Thy-1 expression in glomerular podocytes. Because the expression of endogenous Thy1.2 remains unaffected and the ectopic expression in podocytes is observed in all Thy-1-expressing mice carrying the T or mhT constructs (but not the mouse Thy-1 gene only or the hT construct), we conclude that the human Thy1 gene $3^{\prime}$ segment carries a cis-acting element capable of contributing to expression in podocytes. On the other hand, the hT construct that contains a different segment of the human Thy-1 gene led to high expression of the transgene in the kidney proximal tubular epithelium. Similarly, we conclude that the central part of the human Thy-1 gene contains cis-acting sequences that, in combination with the other regulatory elements, direct Thy- 1 expression in proximal tubular epithelium. It should be noted that neither construct caused Thy-1 expression on the mesangial cells, on which it is found in the rat (Morris and Ritter, 1980; for review, see Crawford and Barton, 1986).

Both patterns of ectopic kidney expression produced distinct physiological effects. Podocyte expression of the $T$ and $\mathrm{mhT}$ constructs, at a sufficiently high level (T12, T11, $\mathrm{mhT} 4$ ), caused proteinuria in two of the three mouse lines (T12, mhT4). These express the highest levels of the T construct in their kidneys (Table 1), although the levels of mRNA in mhT4 appear to be lower than those in T11 in Figure $2 \mathrm{~b}$. This is because the kidneys of this animal were in an advanced diseased state and show the same pattern of expression as that observed for the T12 adult sick animals (Figure 2b), i.e., low transgene but high endogenous Thy-1 expression. Interestingly, the onset of proteinuria in T12 is associated with a rise in transgene expres- 

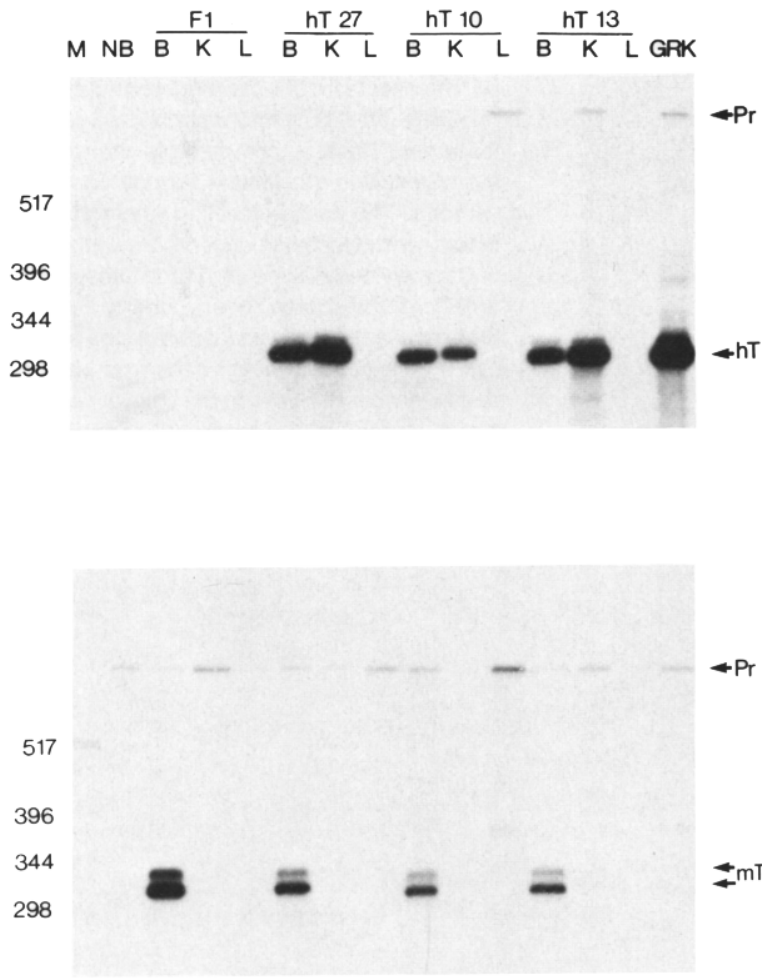

Figure 5. Measurement of Steady-State mRNA Levels of Transgenic Mouse Tissues Carrying the hT Gene Construct

Top: Ten micrograms of total RNA from a human neuroblastoma cel line (NB), brain (B), kidney (K), liver (L), and the kidney cells that were derived from the hT10 neoplasm and established in culture (GRK; see text and Figure 7) were hybridized to a 960 nucleotide BstEll-Apal human Thy-1 probe (Pr). Normal transcription of the hT transgene produces an mRNA that protects 320 nucieotides of the above probe from $\mathrm{S1}$ digestion (hT). Sizes were estimated from an end-labeled Hinfl digest of pBR322 DNA. After longer exposures of the autoradiograph (not shown), the positive control lane NB gave a detectable signal at the expected size. All other negative lanes remained negative. Bottom: The same as top panel but with an 800 nucleotide BstEll-Apal mouse fragment as a probe ( $\mathrm{Pr}$ ). In this case only the endogenous Thy1.2 mRNA will protect 320 nucleotides of the probe from $\$ 1$ nuclease digestion (mT)

sion in the kidney (Figure 2b). This is not caused by podocyte proliferation or expression of Thy-1 on other cell types. Therefore, this suggests that when the Thy-1 on the podocytes in T12 and mhT4 reaches a certain level, their function in maintaining the filtration barrier of the basement membrane is perturbed, and proteinuria results. There are several circumstances in other animals where proteinuria follows either a toxic insult or a metabolic abnormality and where the podocyte seems to be the affected cell. In humans, the spontaneous metabolic abnormality in Fabry's disease results in the accumulation of ceramide trihexoside in many cells in the body, and the podocyte is prominently affected. Proteinuria is present and the glomeruli develop focal and segmental hyalinosis or sclerosis (Heptinstall, 1978). In the rat, the podocytes appear especially sensitive to purine aminonucleoside both in vitro (Fishman and Karnovsky, 1985) and in vivo. In the

\begin{tabular}{|c|c|c|c|c|c|}
\hline \multicolumn{6}{|c|}{$\begin{array}{l}\text { Table 1. Levels of Transgenic Thy- } \\
\text { in Brain and Kidney as Measured b } \\
\text { Transgene }\end{array}$} \\
\hline & & Brain & Kidney & Brain & Kidney \\
\hline \multicolumn{6}{|c|}{ T Constructs } \\
\hline \multicolumn{2}{|c|}{$\begin{array}{ll}\text { T12 } & 8 \text { days } \\
& \text { Littermates }\end{array}$} & $0^{1.00}$ & $\begin{array}{l}0.035 \\
0\end{array}$ & $\begin{array}{l}0.30 \\
0.30\end{array}$ & $\begin{array}{l}0.010 \\
0.010\end{array}$ \\
\hline \multicolumn{2}{|c|}{$\begin{array}{ll}\mathrm{T} 12 & 11 \text { days } \\
& \text { Littermates }\end{array}$} & $0^{1.00}$ & $\begin{array}{l}0.030 \\
0\end{array}$ & $\begin{array}{l}0.35 \\
0.40\end{array}$ & $\begin{array}{l}0.006 \\
0.006\end{array}$ \\
\hline \multicolumn{2}{|c|}{$\begin{aligned} \text { T12 } & 30 \text { days } \\
& \text { Littermates }\end{aligned}$} & $0^{6.5}$ & $\begin{array}{l}0.030 \\
0\end{array}$ & $\begin{array}{l}0.90 \\
0.95\end{array}$ & $\begin{array}{l}0.003 \\
0.003\end{array}$ \\
\hline \multicolumn{2}{|c|}{$\begin{aligned} \text { T12 } & 60 \text { days } \\
& \text { Littermates }\end{aligned}$} & $\begin{array}{l}10.0 \\
0\end{array}$ & $\begin{array}{l}0.010 \\
0\end{array}$ & $\begin{array}{l}0.95 \\
1.00\end{array}$ & $\begin{array}{l}0.0025 \\
0.0025\end{array}$ \\
\hline \multicolumn{2}{|c|}{$\begin{array}{l}\text { T11 } 60 \text { days } \\
\text { mhT Constructs }\end{array}$} & 6.5 & 0.010 & 1.00 & 0.0025 \\
\hline \multicolumn{2}{|c|}{$\begin{array}{l}\text { mhT4 } 5 \text { months } \\
\text { hT Constructs }\end{array}$} & 10.0 & 0.025 & n.d. & n.d. \\
\hline \multicolumn{2}{|c|}{ hT10 } & 1.6 & 1.00 & 1.00 & 0.0025 \\
\hline \multicolumn{2}{|c|}{$h+13$} & n.d. & 1.00 & n.d. & n.d. \\
\hline \multicolumn{2}{|c|}{ hT27 } & n.d. & n.d. & n.d. & n.d. \\
\hline \multicolumn{2}{|c|}{ hTd1 } & 1.00 & 1.00 & 0.20 & 0.002 \\
\hline \multicolumn{2}{|c|}{ hTd2 } & 0.25 & 1.00 & 0.20 & n.d. \\
\hline \multicolumn{2}{|c|}{ hTd3 } & 0.07 & n.d. & 0.30 & n.d. \\
\hline \multicolumn{2}{|c|}{ Littermate to hTd1-3 } & 0 & 0 & 0.25 & 0.002 \\
\hline \multicolumn{2}{|c|}{$\begin{array}{l}\text { GRK cells, uncloned } \\
16 \text { cell lines selected } \\
\text { in D-valine }\end{array}$} & - & 1.00 & - & n.d. \\
\hline \multicolumn{6}{|c|}{20 cell lines requiring } \\
\hline & aline & - & $0.15-0.90$ & - & 0.001 \\
\hline
\end{tabular}

Levels are relative to the level in normal adult brain, which is taken as 1.0. Thy 1.1 transgene measured in T and mhT mice by absorption of OX7 monoclonal antibody, compared to absorption of adult AKR mouse brain homogenate. Human Thy-1 transgene measured by absorption of F15-42-1-5 monocional antibody, compared to absorption by a sample of human brain homogenate. Endogenous Thy-1.2 measured by absorption of $30 \mathrm{H}-12$ monoclonal antibody, compared to absorption by adult C57BI $\times$ CBA mouse brain homogenate. n.d., not determined.

intact animal, administration of the drug is followed after a few days by the development of proteinuria: the podocytes show striking ultrastructural changes (Caulfield et al., 1976). Subsequently, there is the development of mesangial hypercellularity, and animals that survive the acute phase of the disease subsequently develop widespread glomerulosclerosis (Diamond and Karnovsky, 1986).

Interestingly, administration of anti-thymocyte, or antiThy-1, antibodies in both humans and rats can also lead to glomerulonephritis (Cunningham et al., 1987; Bagchus et al., 1986; Ishizaki et al., 1986). However, certainly in the case of anti-Thy-1 antibodies in the rat, the mesangial cells, rather than the podocytes, constitute the primary target tissue, and the disease is immune-related (Bagchus et al., 1986). In our case, there is no evidence for immune involvement during the onset of proteinuria, which appears to be a direct result of ectopic Thy-1 expression. 


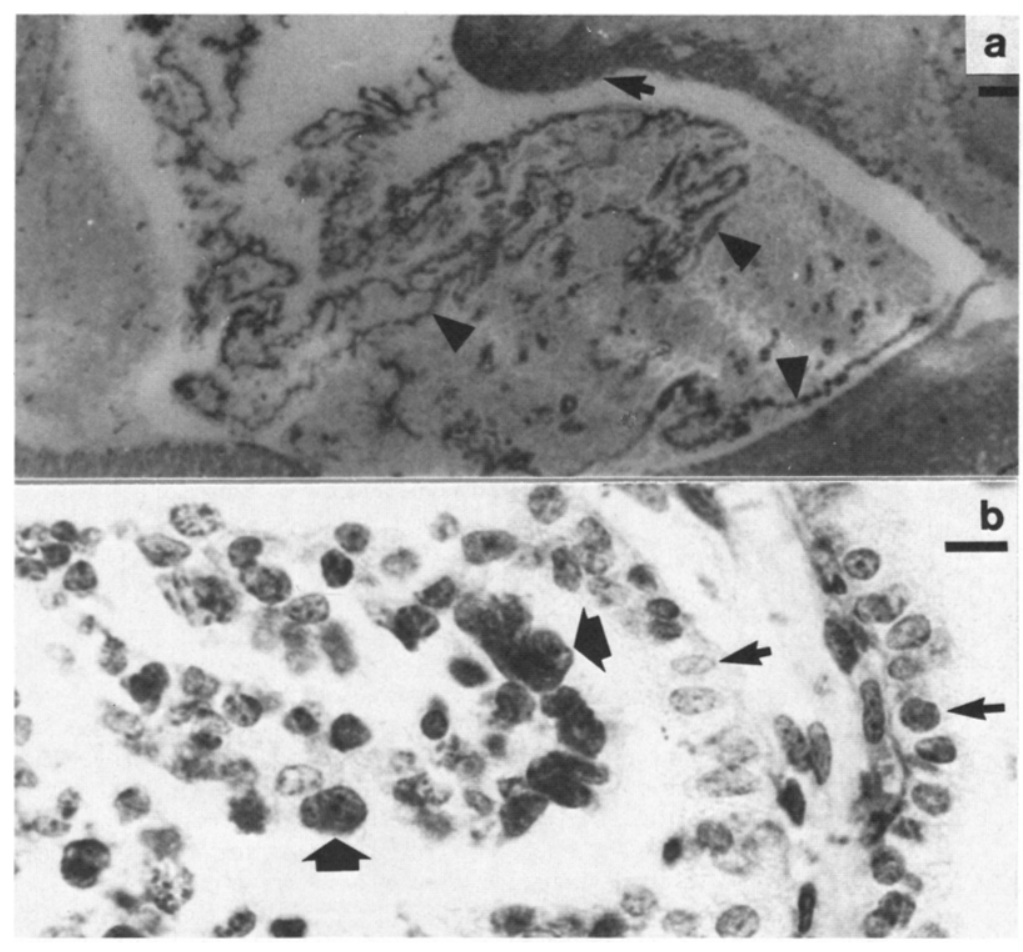

Figure 6. Neoplasm of Choroid Plexus, immunolabeled for Human Thy-1

(a) The neoplasm fills the third ventricle and is relatively weakly immunoperoxidase-labeled for human Thy-1, as compared to strong labeling of axons in the fimbria (arrow) above the ventricle. The intense labeling within the neoplasm (arrowheads) is observed with the secondary antibody alone (or in the presence of anti-Thy-1.1 antibody), and is due to reaction with mouse $\mathrm{lg}$ in the vasculature of the plexus. (b) High-power view of the neoplasm showing relatively normal nuclei in the cells around the blood vessel (small arrows) and disorganized neoplastic cells containing atypical nuclei (large arrows). Scale bars are $100 \mu \mathrm{m}$ (a) and $10 \mu \mathrm{m}$ (b).

In the case of the $\mathrm{hT}$ constructs, proteinuria also characterized the development of a renal abnormality, but in this case it is probably the result of glomerular disruption caused by invasion of neoplastic proximal tubular epithelium. The primary lesion appeared to be the uncontrolled proliferation of these epithelial cells, giving rise to a cystic neoplasm. The cell lines derived from the hT10 kidney appear to be all epithelial, as expected from this neoplasm, yet they show several differences in morphology (Figure 7). Moreover, most proximal tubules in all hT animals develop this neoplasm, and it seems therefore highly unlikely that the neoplasm is the result of a single cell clone in each animal, but rather of a population of cells. These give rise to different, continually proliferating cell lines in culture, each containing high levels of the transgenic Thy1 , which suggests an a priori case for the involvement of Thy-1 in proliferation. Whether the proliferation is the result of a blockage of terminal differentiation of tubular epithelial cells by the expression of Thy- 1 on their cell surface, or that Thy-1 antigen is the primary stimulator for proliferation by an autocrine-type mechanism as, for example, observed for some oncogenes, is not yet clear. However, the fact that all the cells that proliferate in culture express Thy- 1 suggests that the latter might be the case.

The occurrence of a neoplasm of the choroid plexus epithelium in one $\mathrm{hT}$ animal is particularly intriguing, given the similarity of this tissue to the kidney proximal tubules. Both tissues are an epithelial monolayer involved in the selective interchange of molecules to and from the bloodstream.

Indication of a role for Thy- 1 in cellular proliferation is more advanced in the lymphoid system, where anti-Thy-1 antibodies, acting through the T3/Ti system on intracellular $\mathrm{Ca}^{2+}$ levels, cause proliferation of $\mathrm{T}$ lymphocytes (Kroczek et al., 1986b; Gunter et al., 1987). It will be interesting to determine whether a similar pathway is used in the proximal tubular epithelium, and why high levels of expression of Thy-1 fail to reactivate podocytes.

\section{Experimental Procedures}

Hybrid Gene Construction and Production of Transgenic Mice The hybrid gene named T (Figure 1) was constructed by fusion of a 5.7 $\mathrm{kb}$ EcoRl-Apal mouse Thy-1.1 gene fragment containing the first four exons (including exons la and $\mathrm{Ib}$ ) and part of exon IV to a $3.4 \mathrm{~kb}$ Apal-EcoRI human Thy-1 DNA sequence containing the remaining noncoding part of exon IV plus $3^{\prime}$ human flanking sequence. The mhT hybrid gene was constructed by the addition to the $\mathrm{T}$ hybrid gene of a $1.3 \mathrm{~kb}$ Sall-EcoRI fragment derived from the $5^{\prime}$ upstream flanking region of the mouse Thy-1.1 gene. Finally, the EcoRI-EcoRI fragment containing the mouse Thy-1.2 gene was the basis for the construction of the $\mathrm{hT}$ hybrid gene, which was formed by replacement of a $0.8 \mathrm{~kb}$ BstEll-Apal fragment containing the coding part of exons III and IV with the homologous $0.96 \mathrm{~kb}$ BstEII-Apal human Thy-1 gene fragment.

Linear DNA fragments were excised from vector sequences with the appropriate restriction enzymes, separated on low melting agarose gels, isolated, and used for microinjection. F2 hybrid mouse zygotes of CBA $\times$ C57Bl/10 parents were isolated, and pronuclei were injected with a solution containing approximately $2 \mu \mathrm{g} / \mathrm{ml}$ DNA fragments in TE buffer (10 mM Tris, pH 7.5; $0.1 \mathrm{mM}$ EDTA). Eggs surviving the microinjection were transferred into the oviducts of recipient pseudopregnant females (for review, see Brinster et al., 1985). Ten days after birth, pups were analyzed for the presence of intact injected DNA by Southern blot analysis of tail genomic DNA (Southern, 1975).

Purification and Analysis of RNA from Mouse Tissues Whole tissues were washed in PBS, and cells were lysed by homogenization in 5-10 ml of ice-cold $3 \mathrm{M} \mathrm{LiCl}, 6 \mathrm{M}$ urea (Auffray and Rougeon, 1980). The homogenate was mixed overnight at $4^{\circ} \mathrm{C}$ and the next morn- 


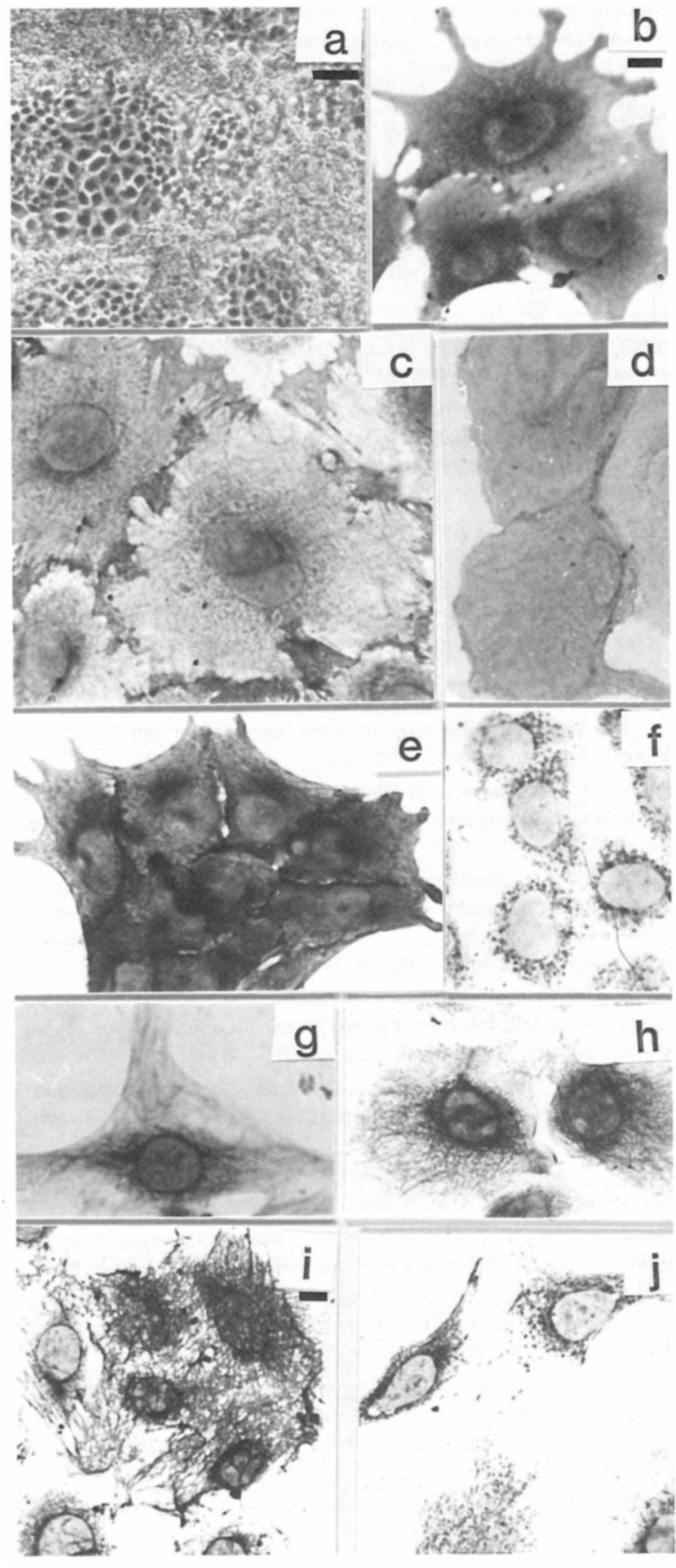

Figure 7. Cell Lines Derived from hT10 Kidney Have Diverse Epithelial Properties

(a) Phase contrast of primary culture of GRK cells 2 weeks after plating out, showing large flat cells surrounded by smaller cells that pile up. Scale bar is $50 \mu \mathrm{m}$. (b-j) Show cell lines grown for $72 \mathrm{hr}$ on plastic coverslips and then immunoperoxidase-stained for human Thy-1 (b-e), monoclonal antibody $4 \mathrm{~F} 1$ to epithelial cells $(\mathrm{f})$, cytokeratin $(\mathrm{g}, \mathrm{h})$, and fibronectin (i, j). Cell lines are L9 (b), L4 (c, g, i), D.F1 (d), and D.C1 (f, $h, j)$. The prefix " $D$ " denotes a line selected for in D-valine; $L$, a line that requires $\mathrm{L}$-valine. Differences in intensity of staining for human Thy-1 and cell morphology can be seen (b-e). L4 (i) is typical of some lines in secreting extracellular fibronectin, in this case covering four cells D.C1 (j) is typical of other lines for which the fibronectin staining is cellular. Antibodies to non-kidney epithelia failed to give any staining (not shown). Scale bar (b) is $10 \mu \mathrm{m}$; (c-j) are at same magnificatlon. ing RNA was pelleted. After a brief wash in $2 \mathrm{mll}$ of the same ice-cold $\mathrm{LiCl}-\mathrm{urea}$ solution and recentrifugation, the FNA pellet was resuspended in $500 \mu \mathrm{l}$ of a $10 \mathrm{mM}$ Tris (pH 7.6), $1 \mathrm{mM}$ EDTA, $0.5 \%$ SDS solution followed by phenol/chloroform extraction and ethanol precipitation. Concentrations were determined from absorbance at $260 \mathrm{~nm}$ and confirmed by electrophoresis on $2 \%$ agarose gels. The latter also showed that the RNA preparations were undegraded. S1 nuclease analysis of Thy-1-specific mRNA was performed as described elsewhere (Kollias et al., 1987). RNA was hybridized to a 680 nucleotide BamHI (Figure 2a) or 340 nucleotide Hinfl (Figure 2b) $3^{\prime}$ end-labeled probe from the $3^{\prime}$ end of the Thy-1.2 gene and a 950 nucleotide NcolBglll $3^{\prime}$ end-labeled probe from the $3^{\prime}$ end of the human Thy- 1 gene (Pr). Normally, transcription from the endogenous Thy-1.2 gene produces an mRNA that protects a probe fragment of 115 or 210 nucleotides from $\mathrm{S} 1$ nuclease digestion (mT). Normal transcription from the $\mathrm{T}$ or $\mathrm{mhT}$ transgenes produces a major mRNA that protects a probe fragment of 165 nucleotides from $S 1$ digestion (hT). A minor band at 400 nucleotides represents a second poly(A) addition site for the transgenic mRNA (hT). Sizes were estimated from an end-labeled Hinfl digest of pBR322 DNA (lane M).

\section{Immunohistochemical and Histological Analysis}

One kidney from each animal was cut transversely into four sections, one of which was snap-frozen by immersion in isopentane/liquid nitrogen, sectioned on a cryostat, and analyzed for deposition of mouse $\operatorname{lgG}$, lgM, and third component of complement (fluorescein-conjugated sheep anti-mouse $\operatorname{lgM}$ and rhodamine-conjugated rabbit anti-mouse IgG were from Miles; goat anti-mouse C3 was from Nordic). Another segment was fixed by immersion in formalin and processed through paraffin wax for histological examination; a third segment was fixed in $1 \%$ glutaraldehyde $1 \%$ paraformaldehyde in $100 \mathrm{mM}$ phosphate buffer (pH 7.4), osmicated, embedded in Epon, and stained in lead citrate before examination in the electron microscope. The final segment was fixed in $95 \%$ ethanol/5\% acetic acid and embedded in polyester wax, and $5 \mu \mathrm{m}$ sections were stained for Thy-1.1, Thy-1.2, or human Thy-1. These different forms of Thy- 1 were detected by usirg monoclonal antibodies OX7 (Mason and Williams, 1980), 30H-12 (Ledbetter and Herzenberg, 1979), and F15-42-1-5 (Dalchau and Fabre, 1979), respectively. In immunohistochemistry these were routinely visualized with a horseradish peroxidase-conjugated second antibody, either our own affinity-purified rabbit $F(a b)_{2}$ anti-mouse IgG (Kollias et al., 1987) or, for the rat monocional $30 \mathrm{H}-12$, a rabbit anti-rat IgG (DAKO) that was first absorbed with mouse serum to remove antibodies cross-reacting with endogenous $\mathrm{lg}$ in the capillaries, and in damaged kidneys, the mesangium. Detection of the transgene products, whether Thy-1.1 or human Thy -1 , was done with mouse monoclonals, and reaction of the second antibody was endogenous ig was potentially a problem. However, the concentration of both transgenic products was so high in kidney that simply using the second antibody at a high dilution $(2 \mu \mathrm{g} / \mathrm{ml})$ enabled visualization of the transgenic Thy-1 with minimal detection of endogenous lg. Use of our normal concentration of second antibody $(20 \mu \mathrm{g} / \mathrm{ml})$ gave more intense staining of the transgenic product, and also endogenous ig labeling, but revealed no further cell types expressing the transgene. In addition, for detecting the $T$ and $\mathrm{mhT}$ constructs, we used a directly horseradish peroxidase-conjugated $\mathrm{F}\left(\mathrm{ab} \mathrm{b}_{2}\right)_{2}$ of $\mathrm{OX} 7$ antibody. and obtained the same pattern of specific labeling as found with the indirect conjugates.

\section{Radioimmunoassays}

These were done as previously described for Thy-1.1 and Thy-1.2 (Kollias et al., 1987). Human Thy-1 was measured by the same method, using $0.25 \mu \mathrm{g} / \mathrm{ml}$ of F15-42-1-5 lgG as the first antibody, and residual antibody activity remaining after absorption was back-titered onto 100 $\mu \mathrm{g}$ of human brain membranes. Homogenates of adult AKR, CBA $\times$ $\mathrm{C} 57 \mathrm{~B}$, or human brain were used as standards in measuring Thy-1.1, Thy-1.2, and human Thy-1, respectively. Neither mouse brain or kidney, or human brain, gave any absorption of the inappropriate monoclonal antibodies, even at tissue concentrations up to 1000 times greater than that giving absorption of the correct antibody. Similarly, in immunohistochemistry, no cross-reaction of antibodies with inappropriate tissue (e.g., OX7 or F15-42-1-5 with nontransgenic CBA $\times$ C57BI littermate kidney) was seen. 
Assessment of Possible Anti-Thy-1.1 Antibodies in T Mice Serum was collected from four 8-week-old T12 mice homozygous for the $T$ construct, and from three nontransgenic littermates. For each, $50 \mu \mathrm{l}$ was diluted in $150 \mu \mathrm{l} 0.5 \mathrm{M}$ acelic acid and incubated for $2 \mathrm{hr}$ at $4^{\circ} \mathrm{C}$. PBS $(65 \mu l)$ and $2.0 \mathrm{M}$ Tris $(35 \mu \mathrm{l})$ were added to neutralize the $\mathrm{pH}$, the sample was centrifuged at $14,000 \times \mathrm{g}$ for $3 \mathrm{~min}$, and $50 \mu \mathrm{l}$ aliquots with 11 further doubling dilutions were added to $2.5 \times 10^{6} \mathrm{AKR}$ (to measure anti-Thy-1.1) and CBA $\times$ C57BI (to measure anti-thymocyte, including Thy-1.2) antibodies. A separate $50 \mu \mathrm{l}$ aliquot of each serum was diluted in $250 \mu \mathrm{l}$ PBS, and $50 \mu \mathrm{l}$ of this, with 11 further doubling dilutions, was added to each type of thymocyte. After $4 \mathrm{hr}$ the thymocytes were washed twice by centrifugation in $0.1 \%$ bovine serum albumin/PBS, and bound antibody was determined by the binding of ${ }^{125}$-labeled affinity-purified rabbit $F(a b)_{2}$ anti-mouse $1 \mathrm{gG}$ or anti-rat IgG (for $30 \mathrm{H}-12$ ), both at $1 \mu \mathrm{g} / \mathrm{ml}$ and $10 \mathrm{mCi} / \mathrm{mg}$, in $2 \%$ bovine serum albumin/PBS (Morris and Williams, 1975). As positive controls, OX7 $\operatorname{lgG}$ (first dilution, $0.5 \mu \mathrm{g} / \mathrm{ml}$ ), ascitic fluid containing the $\mathrm{lgM}$ monoclonal anti-Thy-1.1 NIM-M131 (Thomas et al., 1986) (first dilution 1:200), and $30 \mathrm{H}-12$ (culture supernalant starting from 1:10) were included. In a further experiment, serum from four 4-week-old T12 heterozygotic mice and three littermates was similarly assayed without acid dissociation of immune complexes being included.

\section{Proteinuria Development}

Samples of urine were collected in microcentrifuge tubes each week, and $5 \mu \mathrm{l}$ aliquots were boiled with $20 \mu$ l of nonreducing sample buffer and electrophoresed on $8 \%$ SDS-polyacrylamide gels, which were stained with Coomassie brilliant blue.

\section{Establishment of Cell Lines}

A portion of hT10 kidney was removed sterilely, teased apart with forceps in $10 \%$ fetal calf serum/RPMI 1640 medium, and cultured at $37^{\circ} \mathrm{C}$ in the same medium. Cells were cloned by limiting dilution in 96 -well plates, using either the above medium or L-valine-free medium containing D-valine (Gilbert and Migeon, 1975) to select against fibroblasts. Clones selected in the latter medium were transferred to $5 \%$ fetal calf serum $/ 5 \%$ newborn calt serum in RPMI 1640 , and are given the prefix " $D$ " in their name. Clones selected in normal medium were transferred to three wells of a 48-well culture dish. Two of the wells contained normal medium; the third contained the D-valine medium. Where clones failed to survive in the D-valine medium but reached confluency in the two wells containing normal medium, the medium in one of the latter was substituted by $D$-valine medium. If all the cells then died (usually over $48 \mathrm{hr}$ ), the clone was taken to lack D-amino acid oxidase, the enzyme requlred for survival in medium containing the $D$, but not $L$, form of valine (Gilbert and Migeon, 1975). Such clones were then grown in $5 \%$ fetal $/ 5 \%$ newborn calf serum, and are given the prefix " $L$ " in their name. For all clones, the amount of human Thy- 1 was measured by radioimmunoassay, and the amount of Thy-1.2 similarly measured on five $D$ and five $L$ clones. Two $L$ and five $D$ clones were also grown on plastic coverslips, fixed in methanol, and immunoperoxidase-stained for Thy-1.2 and human Thy-1 as before. In addition, these cells were stained with antibodies to cytokeratin (DAKO), fibronectin (Morris and Beech, 1984), and rat monocional antibody 4F1 specific for thymic cortical epithelia and renal tubular epithelia (Ritter et al., unpublished data); the tissue reactivity of this antibody is equivalent to the mouse monoclonal antibody MR6 reacting with human epithelium (de Maagd et al., 1985). To assess whether these cells gave transplantable tumors, $10^{7}$ of the uncloned GRK cells were injected Intraperltoneally, or $2 \times 10^{6}-10^{7}$ cloned cells of three D-type and three L-type lines were injected subcutaneously, into two NIMR:NIMR-nv nude mice. The mice were followed for 2 months (GRK cells) or one month (cell lines) for signs of tumor development.

\section{Acknowledgments}

We are grateful to $M$. Johnson, A.-B. Kolsto, and A. Westmuckett for technical assistance; to C. O'Carroll for the preparation of the manuscript; and to R. Dalchau, A. F. Williams, and B. Thomas for the gifts of their monocional antibodies. G. Kollias was supported by a longterm EMBO fellowship and by the International Spinal Research Trust. This work was supported by the MRC (U.K.).

The costs of publication of this article were defrayed in parl by the payment of page charges. This article must therefore be hereby marked "advertisement" in accordance with 18 U.S.C. Section 1734 solely to indicate this lact.

Received July 14, 1987.

\section{References}

Auffray, C., and Rougeon, F. (1980). Purification of mouse immunogiobulin mRNAs from total myeloma tumour RNA. Eur. J. Biol. 107, 303-314.

Bagchus, W. M., Hoedemaker, P. J., Rozing, J., and Bakker, W. W. (1986). Glomerulonephritis induced by monoclonal anti-Thy-1.1, antibodies. Lab. Invest. 55, 680-687.

Brinster, R. L., Chen, H. Y., Trumbauer, M. E., Yagle, M. K., and Palmiter, R. D. (1985). Factors affecting the efficiency of introducing foreign DNA into mice by microinjecting eggs. Proc. Natl. Acad. Sci. USA $82,4438-4442$.

Caulfield, J. P., Reid, J. J., and Farquhar, M. G. (1976). Alterations of the glomerular epithelium in acute aminonucleoside nephrosis. Lab. Invest. 34, 43-59.

Crawford, J. M., and Barton, R. W. (1986). Biology of disease, Thy-1 glycoprotein: structure, distribution and ontogeny. Lab. Invest. 54 , 122-135.

Cunningham, F., Chi, Y., Brentjens, J., and Venulo, R. (1987). Acute serum sickness with glomerulonephritis induced by anti-thymocyte globulin. Transplantation 43, 309-312

Daichau, R., and Fabre, J. W. (1979). Identification and unusual tissue distribution of the canine and human homologues of Thy-1. J. Exp. Med. 149, 576-591.

de Maagd, R. A., Mackenzie, W. A., Schuurman, H-J., Ritter, M. A., Price, K-M., Broekhuizen, R., and Kater, L. (1985). The human thymus microenvironment: heterogeneity detected by monoclonal anti-epithelial antibodies. Immunology 54, 745-754.

Diamond, J. R., and Karnovsky, M. J. (1986). Focal and segmental glomerulosclerosis following a single intravenous dose of Puromycin aminonucleoside. Am. J. Path. 122, 481-487.

Fishman, J. A., and Karnovsky, M. J. (1985). Effects of the aminonucieosides of puromycin on glomerular epithelial cells in vitro. Am. J. Path 118, 398-407.

Giguere, V., Isobe, K-1., and Grosveld, F. (1985). Structure of the murine Thy-1 gene. EMBO J. 4, 2017-2024.

Gilbert, S. F., and Migeon, B. R. (1975). D-Valine as a selective agent for normal human and rodent epithelial cells in culture. Cell $5,11-17$. Gunter, K. C., Malek, T. R., and Shevach, E. M. (1984). T-cell activating properties of an anti-Thy-1 monoclonal antibody: possible analogy to OKT3/Leu-4. J. Exp. Med. 159, 716-730.

Gunter, K. C., Germain, R. N., Kroczek, R. A., Saito, T., Yokoyama W. M., Chan, C., Weiss, A., and Shevach, E. M. (1987). Thy-1 mediated T-cell activation requires co-expression of CD3/Ti complex. Nature $326,505-507$.

Heptinstall, R. H. (1978). Pathology of the Kidney, 3rd Edition, Volume III (Toronto: Little Brown and Co.), p. 1667.

Ingraham, H. A., and Evans, G. A. (1986). Characterization of two atypical promoters and alternate mRNA processing in the mouse Thy-1.2 glycoprotein gene. Mol. Cell. Biol. 6, 2923-2931.

Ingraham, H. A., Lawless, G. M., and Evans, G. A. (1986). The mouse Thy-1 gene: complete sequence and identification of an unusual promoter. J. Immunol. 136, 1483-1489.

Ishizaki, M., Masuda, Y., Fukuda, Y., Sugisaki, Y., Yamanaka, N., and Masugi, Y. (1986). Experimental mesangioproliferative glomerulonephritis in rats induced by intravenous administration of anti-Thymocyte serum. Acta Pathol. Jpn. 36, 1191-1203.

Kollias, G., Spanopoulou, E., Grosveld, F., Ritter, M., Beech, J., and Morris, R. (1987). Differential regulation of a Thy-1 gene in transgenic mice. Proc. Natl. Acad. Sci. USA 84, 1492-1496.

Kolsto, A-B., Kollias, G., Giguere, V., Isobe, K-I., Prydz, H., and Grosveld, F. G. (1986). The maintenance of methylation-free islands in transgenic mice. Nucl. Aclds Res. 14, 9667-9678. 
Kroczek, R. A., Gunter, K. C., Germain, R. C., and Shevach, E. M. (1986a). Thy-1 functions as a signal transduction molecule in T lymphocytes and transfected B lymphocytes. Nature 322, 18t-184.

Kroczek, R. A., Gunter, K. C., Seligmann, B., and Shevach, E. M. (1986b). Induction of T cell activation by monoclonal anti-Thy-1 antibodies. J. Immunol. 136, 4379-4383.

Ledbetter, J. A, and Herzenberg, L. A. (1979). Xenogenic monoclonal antibodies to mouse lymphoid differentiation antigens. Immunol. Rev. 47, 63-90.

Low, M. G., and Kincade, P. (1985). Phosphatidylinositol is the membrane-anchoring domaln of the Thy-1 glycoprotein. Nature 378, 62-64.

Low, M. G., Ferguson, R. M. J., Futerman, A. H., and Silman, I. (1986). Covalently attached phosphatidylinositol as a hydrophobic anchor for membrane proteins. Trends Biochem. Sci. 11, 212-215.

Mason, D. W., and Williams, A. F. (1980). The kinetics of antibody binding to membrane antigens in solution and at the cell surface. Biochem. J. 187, 1-20.

Morris, R. J. (1985). Thy-1 in developing nervous tissue. Dev. Neurosci. 7, 133-160.

Morris, R. J., and Beech, J. N. (1984). Differential expression of Thy-1 on the various components of connective tissue of rat nerve during postnatal development. Dev. Biol. 102, 32-42.

Morris, R. J., and Beech, J. N. (1987). Sequential expression of OX2 and Thy-1 glycoproteins on the neuronal surface during development. Dev. Neurosci. 9, 33-44.

Morris, R. J., and Ritter, M. A. (1980). Association of Thy-1 cell surface differentiation antigen with certain connective tissues in vivo. Cell Tissue Res. 206, 459-475.

Morris, R. J., and Williams, A. F. (1975). Antigens on mouse and rat lymphocytes recognized by rabbit antiserum against rat brain: the quantitative analysis of a xenogeneic antiserum. Eur. J. Immunol. 5 , 274-281.

Muller-Sieburg, C. E., Whitlock, C. A., and Weissman, I. L. (1986). Isolation of two early $B$ lymphocyte progenitors from mouse marrow: a committed pre-pre-B cell and a clonogenic Thy-1 ${ }^{10}$ hematopoietic stem cell. Cell 44, 653-662.

Reit, A. E., and Allen, J. M. (1964). Specificity of antisera against leukemic and thymic lymphocytes. Nature 200, 1332-1333.

Ritter, M. A., Morris, R. J., and Goldschneider, I. (1980). Hidden Thy-1 antigen in a subpopulation of mouse bone marrow cells. Immunology 39, 375-383.

Ritter, M. A, Sauvage, C. A., and Delia, D. (1983). Human Thy-1 antigen: cell surface expression on early $T$ and $B$ lymphocytes. Immunology 49, 555-564.

Seki, T., Spurr, N., Obata, F., Goyert, S., Goodfellow, P., arid Silver, J. (1985). The human Thy-1 gene: structure and chromosomal location. Proc. Natl. Acad. Sci. USA 82, 6657-6661.

Southern, E. (1975). Detection of specific sequences among fragments separated by gel electrophoresis. J. Mol. Biol. 98, 503-517.

Stern, P. L. (1973). Thy-1 alloantigen on mouse and rat fibroblasts. Nature New Biol. 246, 76-78.

Thomas, D. B., Giguere, V., Graham, G. M., and Oliveira, O. L. P. (1986). Autoimmunity to Thy-1. Eur. J. Immunol. 16, 40-47.

Tse, A. G. D., Barclay, A. N., Watts, A., and Williams, A. F. (1985). A glycophospholipid tail at the carboxy terminus of the Thy-1 glycoprotein of neurons and thymocytes. Science 230, 1003-1008.

Williams, A. F. (1985). Immunoglobulin-related domains for cell surface recognition. Nature 374, 579-580.

Willams, A. F., and Gagnon, J. (1982). Is the Thy-1 glycoprotein of neuronal cell membranes like the primordial immunoglobulin domain? Science 216, 696-703. 